\title{
Modular Design Guideline fOR Projects From Scratch
}

\author{
Georgy Klushin, Clement Fortin \& Zeljko Tekic
}
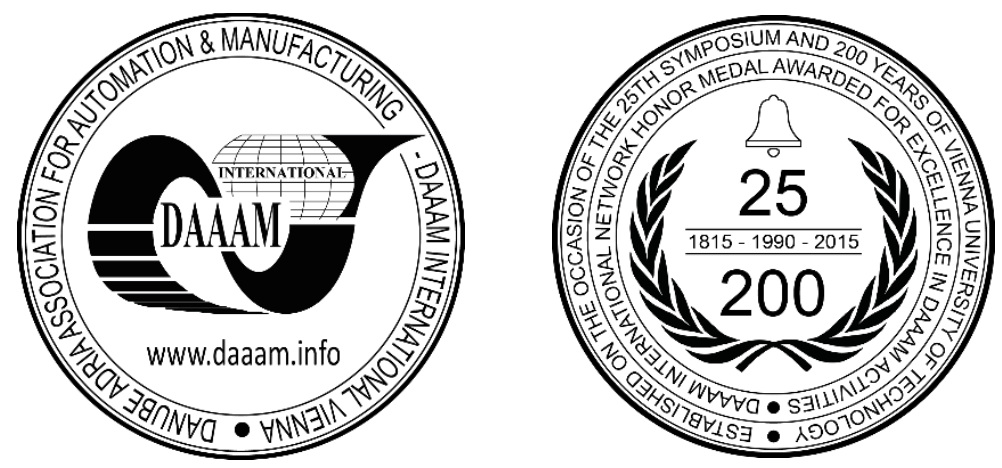

This Publication has to be referred as: Klushin, G[eorgy]; Fortin, C[lement] \& Tekic, Z[eljko] (2018). Modular Design Guideline for Projects from Scratch, Proceedings of the 29th DAAAM International Symposium, pp.0829-0837, B. Katalinic (Ed.), Published by DAAAM International, ISBN 978-3-902734-20-4, ISSN 1726-9679, Vienna, Austria DOI: $10.2507 / 29$ th.daaam.proceedings.120

\begin{abstract}
This article is aimed to help teams that are involved in the development of modular products from scratch. Analysis reveals that a systematic approach to modular design is absent, although, different methods and tools to support modular product development are available on a case-by-case basis without generalization for further turnkey implementation. In general, these methods target a specific industry; most of them are aimed at big companies and require time-consuming adaptation. For these reasons, projects from scratch require significant time at the initial stage of product development to investigate various approaches and align them with project goals. To help teams to deal with the modular design from scratch and thus save time, we introduce a design technique based on setting the modular design guideline that enables the immediate launch of the development process, while applying specific modular design approaches in parallel. Through a case study, it has been demonstrated that the proposed modular design guideline methodology can provide the efficient approach to modular design and save time at the initial stage of development.
\end{abstract}

Keywords: modular design; modularization; design guideline; design method; design management

\section{Introduction}

Modular design, also called platform approach [1], is a core element of mass customization that has evolved significantly over the last 20 years [2], [3]. The modular design essentially provides a relatively small and manageable product structure variety [4] and distinct manufacturing advantages [5]. However, implementation of modular design requires a high initial time investment [6] which can be an obstacle for efficient modular design implementation in projects from scratch. Various methods and tools to support modular product development are available in the literature (for example, [7]-[9]). In general, each proposed method targets a specific industry; most of them are aimed at big companies and require time-consuming, inevitable adaptation [4]. As a result, applying modular design, developers are facing a dichotomy. On the one hand, they always have time limitations for development from scratch, and on the other hand, significant time should be spent on investigating different approaches to modular design. The purpose of this paper is to overcome the obstacle of modular design for projects from scratch and to reduce the initial time investment for investigation of the modular design foundation. We achieved this result by introducing a design technique based on setting modular design guideline that allows to start development immediately and learn specific modular design approaches in parallel. The remainder of the paper is organized as follows. In section 2 we review the relevant literature. 
Section 3 corresponds the reviewed modular design foundation with two modular products from the automotive industry and presents results. After this, we introduce a case study and discuss the practical implications of the proposed design method. Finally, in Section 5 we conclude with a summary of results, limitations and future research directions.

\section{State of the art}

The first industrial sector, which implemented the concepts of modular design, was the machine tools industry in the 1930s [10]. Since that time, modular design filled different objectives for the industry: starting from reducing the renewal cost of equipment and creation of different structural configurations [10]; to enhancing the reasonable disposability and reuse [11] and using a world-class supply network [12].

At the beginning of the 90s, modular design started to be a subject of academic interest. However, modular design has been essentially developed based on longstanding practical experience together with the trial and error method [10]. The extraction of a generalized design method from real products is hard to achieve even for experienced developers, and the design methodology is often represented in the form of "patchwork with holes" as stated by M. Andreasen [13]. The use of the documented approach usually requires significant work on adaptation [4]. Moreover, it is possible to observe that modular design is not sufficiently established as a standalone methodology and is often considered as an additional method to the overall design process [14], [15]. Nevertheless, almost all published research works on modular design can be related to the four principles proposed by Y. Doi [16]: separation, unification, connection, and adaptation which set a common direction for the modular design implementation.

The recent systematic literature review by Jeremy Bonvoisin [4] proposed that, in general, there are three approaches to modular design as shown in Figure 1. If there is already an existing product, it is possible to make a modularization. Modularization can be done in two ways: by redesigning some functional carriers (components, parts or physical elements in a product that contribute to a given function or a set of functions [4]) into modules or by identifying and grouping existing parts into modules (Fig. 1). When the development process is started from scratch, it is possible initially to design a product by designing modules for each function (Fig. 1). These approaches rarely exist in a clear form, and usually, it is necessary to deal with all of them simultaneously. Based on the applicability of the modular design approaches (Fig. 2) we can state that the ideal path for modular product development from scratch starts with the design with modules approach and finishes with improvements achieved through modularization (Fig. 2). Developers can start this journey with CAD modeling [17] and the principle of function purity for a single module [18] or use enhanced methods such as the quality function deployment (QFD) matrix with the "modularity" input as one of the design requirements [7].

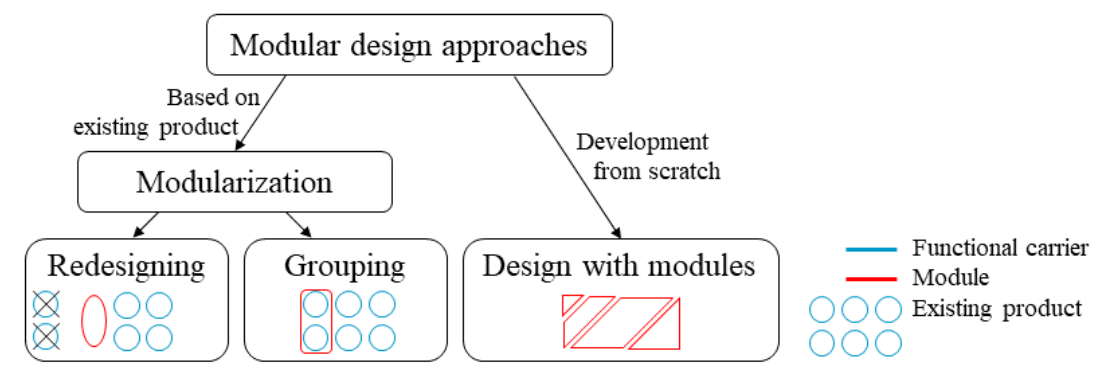

Fig. 1. Three modular design approaches: redesigning, grouping and design with modules

\begin{tabular}{|l|c|c|}
\hline Type of development & $\begin{array}{c}\text { Based on } \\
\text { existing } \\
\text { product }\end{array}$ & $\begin{array}{c}\text { Development } \\
\text { from scratch }\end{array}$ \\
\hline Modular design approach & Works well & $\begin{array}{c}\text { Hard to } \\
\text { implement }\end{array}$ \\
\hline Modularization by redesigning & Works & Works \\
\hline Design with modules & $\begin{array}{c}\text { Hard to } \\
\text { implement }\end{array}$ & Works well \\
\hline
\end{tabular}

Fig. 2. Applicability of modular design approaches in the context of the development type

Apart from the exact context of the selected methodology for modular design, the main objective about the definition of good modular architecture stays the same, the separation must be reasonable including the economic viewpoint, the assembly, the product life-cycle, recycling and other factors [10], [14], [19], [20]. These factors are commonly known as modularization drivers [4] and include attributes such as cost, manufacturing, and after-sales. 
They appear individually for each development process, nevertheless, they can be found with the help of same actions: investigation of the technological trends, customer requirements, market and competitor analyses. These actions are usually already fulfilled at the early stage of new product development. The academic literature provides examples of modularization drivers for different cases, it is possible to observe around 70 of them [4], [7], [9]. Objectives related to the development process of modular products in machine tools [10] and the automotive [21], [22] industries can also be considered as modularization drivers. Following a careful classification and grouping the similar inclusions, a list of 45 drivers can be identified as shown in Table 1.

\begin{tabular}{|c|c|c|c|c|c|}
\hline № & \multicolumn{2}{|c|}{ Modularization Drivers } & № & \multicolumn{2}{|c|}{ Modularization Drivers } \\
\hline 1 & \multirow{6}{*}{ Cost } & Total cost & 23 & \multirow{4}{*}{ Manufacturing } & Tools and methods \\
\hline 2 & & Material cost & 24 & & Manufacturing process \\
\hline 3 & & Labor cost & 25 & & Workforce management \\
\hline 4 & & Capital cost & 26 & & Automatization \\
\hline 5 & & Cost of operation & 27 & \multirow{4}{*}{ Assembly } & Assembly process \\
\hline 6 & & Disposal cost & 28 & & Assembly time \\
\hline 7 & \multirow{5}{*}{ After sales } & Repair and maintenance & 29 & & Assembly organization \\
\hline 8 & & Upgrading & 30 & & Education for assembly \\
\hline 9 & & Adaptation & 31 & \multirow{3}{*}{ Quality } & Separate testing \\
\hline 10 & & Modification & 32 & & Service life \\
\hline 11 & & Recycling & 33 & & Core competency \\
\hline 12 & \multirow{7}{*}{ Design and Development } & Carry-over & 34 & \multirow{2}{*}{ Supply chain } & Global supply \\
\hline 13 & & Time to market & 35 & & Availability and reliability \\
\hline 14 & & Product planning & 36 & \multirow{2}{*}{ Functionality } & Functional purity \\
\hline 15 & & Technology change & 37 & & Functional variety \\
\hline 16 & & Multiple use of & 38 & \multirow{6}{*}{ Sales } & Lead time \\
\hline 10 & & functional carrier & 39 & & Revenue \\
\hline 17 & & Technology push & 40 & & Distribution process \\
\hline 18 & \multirow{4}{*}{ Variance } & Different specifications & 41 & & Distribution organization \\
\hline 19 & & Market variance & 42 & & Market segmentation \\
\hline 20 & & Use variance & 43 & & Market size \\
\hline 21 & & Styling & 44 & \multirow{2}{*}{ Ecology } & End-of-life \\
\hline 22 & Manufacturing & Common unit & 45 & & Environment friendly \\
\hline
\end{tabular}

Table 1. Table of modularization drivers

The specified set of modularization drivers can be used to provide the methodological backbone to define the most suitable modularization principle(s) for the project. Initially and even today, the main method to determine the basic modules is the trial and error method. The first framework for modular design provided only two rules: the one related to single function modules and the other to the interchangeability rule [16]. The approach of allocating a single function to a single module is the most mentioned in the literature [18]. This principle varies from case to case [1] but represents a fundamental direction for a proper modular architecture. Another often mentioned method to support modular design is based on the implementation of a hierarchical structure for product architecture and development process management [23]. Researchers also mention the importance to consider the principle of the cross machines compatibility of modules to achieve a reasonable economy of scale for product families [2], [12], [24], [25]. Going further, the principle of re-using modules can be highlighted as a modern trend for modular design [11], as it provides the opportunity to introduce the final product as a service and enhances easy updates. Special principles can be designed to support the development process, for example, principle of the same size for modules [26], but in general, the goal is to follow the way of grouping together the parts or functional carriers with similar properties and reducing the complexity of interfaces between modules [8]. However, the knowledge alone of all those principles is not sufficient for proper modular product development. To be efficient, these principles should be supported by an overall understanding of the reasons why modular design is implemented, and what value of modular design is expected. In other words, these principles should have the tight connection with modularization drivers. Special tools to support modularization principles can be applied. These tools are developed to work with modularization principles by the congruence of numbers or in the form of automated software to support the decision making [12]. Examples are the tools such as the Design Structure Matrix (DSM) or linear programming in a frame of an optimization problem [12]. A useful tool is the Module Indication Matrix (MIM) method [4]. This tool is based on the construction of a special matrix like QFD or DSM where technical solutions (parts or small assemblies where separation is impossible or unreasonable) are assessed one by one against the modularization driver down through the matrix [7]. Then every technical solution is weighted on a scale of importance. After this, the set of candidates from technical solutions can be selected according to the markings to be considered as modules. The main purpose of these tools is to provide the ability to compare different design alternatives, support decision making and achieve the point where the search of more modules will be ineffective for the overall design [27]. 
In the end, the review of the overall design is required. Modularization metric(s) are used to evaluate the final design of the product. Modularization metrics can be set in quantitative or qualitative [8] manner and results can be presented as a quantitative value or as pass/fail criteria [4]. The process of obtaining results for modularization metrics can be based on measurements and estimations, computations and calculations, algorithms and simulations, scoring systems and graph mappings. The literature can provide more than 100 examples of modularization metrics, for example, size and complexity of the required tool [4], the assembly operation times [7] or level of alignment between the architecture and intellectual property strategy [28]. Modularization metrics will appear individually for each product based on a unique set of modularization drivers and principles. This section showed that academic studies for modular design rapidly clarified and described the design and development of modular architectures. These results are based on the longstanding practical experience of modular design implementation for more than a hundred years. However, the quick research progress generated multiple avenues and created a situation leading to a lack of a comprehensive overview of modular design from the application point of view. The process of modular product design is thus unclear for users, especially in cases of development from scratch where the scope of modular design implementation is almost infinite.

\section{Setting a modular design guideline for project from scratch}

It was shown that the background of the modular design approach is case-based and scattered in terms of methodology. However, according to four principles proposed by Y. Doi we can assume that the logic behind the development of modular products should be case neutral and methods should only be support tools. The common logic appears when the literature corresponds to the observations made in the industrial cases. Based on the questions risen in the previous researches [1], [4], [7], [10], [27], [29], [30], we designed the following questions to extract the logic of development behind modular products: Why modular design was used? Which parts of the product were involved? What was important or expected from the new product? How were the modules generated? and, how was the final design evaluated? These questions were addressed for two products from the automotive industry: the MQB (Modularer QuerBaukasten) platform by Volkswagen and an engine family by BMW.

\subsection{MQB platform by Volkswagen}

The report [21] which contains the strategic and architectural information for the MQB platform was analysed to synthesize the information about the logic of modular design implementation based on the selected questions. The results are presented in Table 2. For each question, the answer in a form of the statement from the report was found. This verifies that the developed questionnaire can serve to understand the logic of the development process for the modular product.

\begin{tabular}{|c|c|}
\hline Why modular design was used? & To decrease the price of the product \\
\hline \multirow{4}{*}{$\begin{array}{l}\text { Which parts of the product } \\
\text { were involved? }\end{array}$} & Underbody \\
\hline & Frame (bodyside, inner / outer crossmember, roof, rear end...) \\
\hline & Hang-on parts (doors, fender, FBP, hood, trunk lid...) \\
\hline & Attached systems (suspensions, axles, powertrain, seating, cockpit...) \\
\hline \multirow{11}{*}{$\begin{array}{l}\text { What was important or } \\
\text { expected from the new product? }\end{array}$} & $\begin{array}{l}\text { Standardization (as much as possible) and enhanced carry-over } \\
\text { (example: central floor) }\end{array}$ \\
\hline & Adding new versions (extend the model range with SUV, crossovers...) \\
\hline & Adaptation for local markets (fulfil the demand of different countries) \\
\hline & Static parameters (torsion, bending, acoustics) \\
\hline & Dynamic parameters (crash tests) \\
\hline & Mass reduction \\
\hline & Increased roominess \\
\hline & Use the same tooling and decreased cost of tooling \\
\hline & Reduced cost of single part \\
\hline & Decreased development cost and time to market for new models \\
\hline & Increased R\&D focus (less projects with more means) \\
\hline \multirow{4}{*}{$\begin{array}{l}\text { How were the modules } \\
\text { generated? }\end{array}$} & By designing common parts (basic systems of the car) \\
\hline & By attachment standardization \\
\hline & By assembly flow (made by modelling and tests) \\
\hline & Around parts over $1 \mathrm{~kg}$ \\
\hline \multirow{4}{*}{$\begin{array}{l}\text { How was the final design } \\
\text { evaluated? }\end{array}$} & Total cost \\
\hline & Number of identical parts \\
\hline & Number of identical fixations \\
\hline & Manufacturing capacity (up to 60 vehicles/hour) \\
\hline
\end{tabular}

Table 2. Q-A to extract logic of modular design, case of MQB platform by Volkswagen 


\subsection{BMW modular powertrain concept}

Recently, BMW applied a modular powertrain concept to both gasoline and diesel engines [22]. The modular platform was designed with the principle of "as much commonality as possible, as much differentiation as necessary" and this framework allows diesel and gasoline engines to share among themselves $35 \%$ common parts. The percentage of common parts for the same fuel type engines is up to $60 \%$. The proposed questions were addressed to investigate the logic of modular design for this case (Table 3). The information in the report [22] provides more insights about the product architecture compared to the first case; however, it is more important to determine that the logic of the development process can be extracted with the developed questionnaire.

\begin{tabular}{|c|c|}
\hline Why modular design was used? & To achieve high degree of commonality across gasoline $\&$ diesel engines \\
\hline \multirow{4}{*}{$\begin{array}{l}\text { Which parts of the product } \\
\text { were involved? }\end{array}$} & Cylinder crankcase \\
\hline & Oil pan \\
\hline & Turbocharger \\
\hline & All together around 50 different modules on the top level \\
\hline \multirow{10}{*}{$\begin{array}{l}\text { What was important or } \\
\text { expected from the new product? }\end{array}$} & Synergy for development and production \\
\hline & Production flexibility (gasoline/diesel, three, four and six cylinders) \\
\hline & Multiple production locations \\
\hline & Increase variants diversity \\
\hline & Standardize interfaces to vehicle \\
\hline & Short reaction time for originating new derivatives (lead-time) \\
\hline & Increase quality level \\
\hline & Economy of scale for purchasing and industrialization \\
\hline & Fuel consumption and emissions (current and future requirements) \\
\hline & Flexibility in assembly process \\
\hline \multirow{3}{*}{$\begin{array}{l}\text { How were the modules } \\
\text { generated? }\end{array}$} & "as much commonality as possible as much differentiation as necessary" \\
\hline & Function-optimized design \\
\hline & To follow optimum cylinder unit (0.5 liters) \\
\hline \multirow{3}{*}{$\begin{array}{l}\text { How was the final design } \\
\text { evaluated? }\end{array}$} & Degree of commonality \\
\hline & Acoustics and emissions (test-cycle measurements) \\
\hline & Number of same interfaces between different engines \\
\hline
\end{tabular}

Table 3. Q-A to extract logic of modular design, case of new engine family by BMW

\subsection{Technique to set a modular design guideline for the project}

The analysis of two case-studies, MQB platform by Volkswagen and the engine family by BMW, revealed that the proposed five questions and answers for them can potentially provide the logic of the modular design implementation for the case product. We inductively conclude that the same set of questions can be used for other modular products (this gives us the major limitation of our study). Finally, to create a support for the design process, this questionnaire was reformulated into a method to set a guideline for the development by matching proposed questions with broad approaches available in academic studies. In this way, the guideline can be used as the main reference point to follow the right logic of modular design implementation, and necessary design methods and tools can be learned and applied iteratively at later stages of the development process; thus, it allows to save time at the initial stage of the development.

The first step is to determine why there is a need to implement the modular design. In the same way, researchers state the strategic objective of the modular design. The clear answer to the question "why modular design is needed" should be provided. An answer to this question should be based on diversity of identified customer's needs, which are going to be satisfied by a new, potentially modular, product. The strategic objective should be aimed to achieve the market fit, performance and competitive advantages of a new system. It should be fixed at the beginning of the design process, and all efforts at the next steps should be in the correspondence with that strategic objective.

The next step is based on the idea of hierarchical structures. Even relatively small products can be split into more manageable blocks (big modules) to implement a hierarchical structure concept. Blocks can represent different domains of a product, like hardware and software, or lay at the same, but represent the different functional aspects. Our recommendation is to create blocks based on the end functions of the device (this approach was shown as a fundamental one to modular design [18]). A similar procedure can be implemented for each block to figure out sub-blocks and so on. The configuration of modular design for each block will be created as a united concept through the next steps.

The third step is to understand which features of the modular design are expected from a manufacturing, assembly, cost and other points of view. This step corresponds to the idea of modularization drivers used in design studies. It means to set directions where to look when the modularization or module generation is performed. 
As it was already mentioned, the modularization drivers appear individually for the product family, and according to the strategic objective, this article contains the table (Table 1) of the most common modularization drivers. Usually, the number of modularization drivers is between six and twelve, and they can appear with individual weights of importance. Then, the developers should agree on the principles for modularization. We suggest starting with the principle of modularization by individual function, which was already proposed to create the hierarchical structure. If it is not sufficient to follow all modularization drivers and make decisions when multiple variants of modularization are possible, other principles can be added. Principles will appear individually for each development process and can be supported with different tools to turn the decision making to the congruence of numbers. Principles are based on selected modularization drivers and the strategic objective and, as in the case of drivers, they can be implemented with weights to minimize the number of conflicting design alternatives.

It can appear that in the end there will be several configurations of modular architecture. For this reason, modularization metrics should be implemented to evaluate the design alternatives and choose the best option. Modularization metrics can be different from the modularization principles used or can represent the same direction. In many cases, the most important assessment criterion is the cost of the solution. However, having only one metric based on the cost can lead to conflicting decisions: the cheapest solution can be hard to use or manufacture and new modularization metrics must be added.

Setting the guideline based on these five steps can help to follow the logic to modular design from scratch and behave as experienced designers working to broaden the approach [31]. This modular design guideline is used to support the development of modular architecture by implementing required design theories on demand within different modular approaches shown in Figure 2. The proposed technique of setting the modular design guideline allows the implementation of modular design approaches in a systematic way to avoid spending time at the initial stage for investigation of the scattered field of the modular design. The case study is presented in the next section, to explain how the modular design guideline can help with the development of a modular product. The graphical representation of the technique to set modular design guideline (Fig. 3) and the short and summarized version are presented at the end of this section:

Technique to set modular design guideline for the project

1. Set a strategic objective

2. Implement a hierarchical structure

3. Select modularization drivers

4. Choose and apply modularization principle(s)

5. Create and measure modularization metric(s)

* Return to previous steps if new knowledge is obtained or improvements are necessary

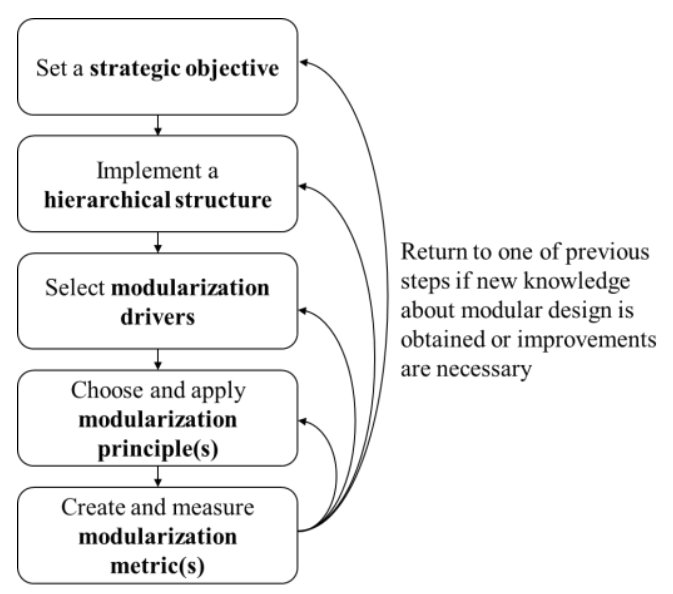

Fig. 3. Technique to set the modular design guideline

\section{Case-study}

The case study is based on the development process of automated retail machines. The project aim is to develop from scratch a family of vending machines to achieve a new level of customization and provide the opportunity to work with a broader selection of goods. Following the market analysis and by the investigation patent data, for example, patents [32]-[34], it was found that the main obstacle for customization of automated retail machines is located within the sophisticated robotic dispense systems, which should be adapted to size and weight of goods. Based on this insight, the first design attempt was to develop adaptable columns, which can store and dispense goods. The modular design guideline for the initial concept is presented in Table 4 (parameters are listed in order of importance). The investigation of the market and development of the first configuration of the modular platform for automated retail took three months to reach the full CAD-prototype. 


\begin{tabular}{|l|l|}
\hline Strategic objective & Enhance customization capabilities \\
\hline \multirow{2}{*}{ Hierarchical structure } & Dispense / storage module (column) \\
\cline { 2 - 2 } & Control module (provides control and payments, includes software) \\
\hline \multirow{3}{*}{ Modularization drivers } & Global supply (implement and adapt market available components) \\
\cline { 2 - 2 } & Re-use (modules can be used several times in different configurations) \\
\cline { 2 - 2 } & Post production changes (enhance implementation of new components) \\
\hline \multirow{2}{*}{ Modularization principles } & Modularization by single function based on technical requirements \\
\cline { 2 - 2 } & Trial and error with support of CAD and physical prototyping \\
\hline Modularization metrics & Total cost (calculation for a "standard configuration") \\
\hline
\end{tabular}

Table 4. First version of modular design guideline used to support the development, case-study

Crucial changes were made after the manufacturing and assembly tests of some modules and initial negotiations with potential clients. Also, the demand for small machines which can work with expensive goods (like laptops or phones) was observed. This new information led to additional modularization drivers, which in turn caused the requirement of additional principles to enhance all drivers in the process of development. Moreover, it forced to rethink the hierarchical structure, as the system appeared to be more complicated than expected. Additional metrics were introduced to make the judgment of the final design more objective. The detailed configuration of the guideline, which was used after the changes, is presented in Table 5. With the help of the suggested method of setting the modular design guideline, continuous improvements in the configuration of modules were achieved.

During that time, the following special approaches to modular design were integrated into the development process: assembly flow as a tool for module generation, use of DSM to support proper interfaces and work with size-adjustable parts [35], methods to estimate the re-use of modules and materials, and procedure for supplier analysis. These approaches were introduced on demand, and in the correlation with all current tasks. As a result, the overall development time was reduced, and three extra months required to produce the prototype, which can be used for pilot installations and negotiations with potential clients. The modular design guideline was a useful tool not only to support design decisions but also to manage the information among developers.

\begin{tabular}{|c|c|}
\hline Strategic objective & $\begin{array}{l}\text { Enhance the marketing capabilities and provide more flexibility in } \\
\text { design (provide the possibility to work with any goods and discover new } \\
\text { unavailable before locations) }\end{array}$ \\
\hline \multirow{6}{*}{ Hierarchical structure } & Dispense / storage module for single good (cell) \\
\hline & Control module (software) \\
\hline & Payment module \\
\hline & Showcase module (based on dispense / storage module) \\
\hline & Coverage module \\
\hline & Statistic of use module (footpath, client's feedback) \\
\hline \multirow{12}{*}{ Modularization drivers } & Total cost and lead time \\
\hline & Adaptation to exact good \\
\hline & Global supply (implement market available components) \\
\hline & Standardization \\
\hline & Supply chain (quick respond, optimization of logistics expenses) \\
\hline & Re-use and carry-over (modules can be used several times) \\
\hline & Manufacturing tools / methods (minimize the number, use widespread) \\
\hline & Assembly process (simplify the assembly process, enhance symmetry) \\
\hline & Adaptation to exact location \\
\hline & External shape variance \\
\hline & Vandal resist and security (reasonable protection of the system) \\
\hline & Beauty and convenience (machine should be attractive) \\
\hline \multirow{5}{*}{ Modularization principles } & By assembly flow (with tools, time and difficulty inputs) \\
\hline & By simplification of interfaces based on DSM \\
\hline & Around size-adjustable parts based on DSM to track size dependencies \\
\hline & Group by material and suppliers \\
\hline & Trial and error with support of CAD and physical prototyping \\
\hline \multirow{4}{*}{ Modularization metrics } & Total cost (calculation for "test machine") \\
\hline & Lead time (measurement) \\
\hline & Assembly process based on scoring system \\
\hline & Re-use (calculation in terms of components cost) \\
\hline
\end{tabular}

Table 5. Final version of modular design guideline used to support the development, case-study 


\section{Discussion and conclusion}

This paper provides support to modular design based on the technique for setting a modular design guideline (Fig. 3) and mainly addressed to projects from scratch. The guideline is based on setting a strategic objective, a hierarchical structure, modularization drivers, modularization principles and modularization metrics to support the development process. The method can be applied to support the design and development of modular architectures for the wide range of new products from different industries. To explain the applicability of this approach, one can consider the different ways to learn a foreign language. The first, "classical" way, is based on attending special courses or individual lessons in the native country and the second one is based on moving to the foreign country where the person will be forced to use the foreign language to secure daily operations. The second way is usually faster but can have trade-offs in the quality of grammar or weak writing skills. Similarly, we can distinguish our modular design approach expressed by the technique for setting a modular design guideline; it can support fast and coherent learning in the "foreign country" of modular design during the development process. The proposed modular design guideline can be used to launch the development process immediately and apply specific modular design approaches in parallel.

We built the approach based on the assumption that the logic of modular design is product neutral and observed it in existing products. We also propose that required methods and tools can be added on demand. The weak point here is that some aspects of a development process are not included in any publications or reports or are not expressed in a comprehensive form. For example, information related to intellectual property (IP) management; it is known that modularity in knowledge allows securing IP rights in different and more secure ways in comparison to the case of united knowledge [36]. For modular products, the modularity in knowledge can appear naturally and can be used to secure IP in different ways, but this requires an initial synchronization between the IP strategy and the product development process, which is not explicitly supported by our approach or any tool available in the literature; however, it's a promising further research avenue.

The authors are also considering further practical applications of the technique for setting a modular design guideline and are open to collaboration with developers willing to use it.

\section{Reference}

[1] Gershenson, J.; Prasad, G. \& Zhang, Y. (2003). Product Modularity: Definitions and Benefits, Journal of Engineering Design, Vol. 14, No. 3, 2003, pp. 295-313, ISSN 09544828, DOI 10.1080/0954482031000091068.

[2] Fogliatto, F., Da Silveira, G., \& Borenstein, D. (2012). The Mass Customization Decade: An Updated Review of the Literature, International Journal of Production Economics, Vol. 138, No. 1, 2012, pp. 14-25, ISSN 09255273, DOI 10.1016/j.ijpe.2012.03.002

[3] Tu, Y., Xie, S. \& Fung R. (2007). Product Development Cost Estimation in Mass Customization, IEEE Transactions on Engineering Management, Vol. 54, No. 1, Feb. 2007, pp. 29-40., ISSN 1558-0040, DOI 10.1109/TEM.2006.889065

[4] Bonvoisin, J., Halstenberg, F., Buchert, T. \& Stark, R. (2016). A Systematic Literature Review on Modular Product Design, Journal of Engineering Design, Vol. 27, No. 7, Jul. 2016, pp. 488-514., ISSN 0954-4828, DOI $10.1080 / 09544828.2016 .1166482$

[5] Stone, R., Wood, K. \& Crawford, R. (2000). A Heuristic Method for Identifying Modules for Product Architectures, Design Studies, Vol. 21, No. 1, Jan. 2000, pp. 5-31., ISSN 0142694X, DOI 10.1016/S0142-694X(99)00003-4

[6] Hackl, J. \& Krause, D. (2017). Towards an Impact Model of Modular Product Structures, Proceedings of the 21st International Conference on Engineering Design (ICED17), Vol. 3: Product, Services and Systems Design, 2017, pp. $151-160$.

[7] Erixon, G. (1996). Modular Function Deployment (MFD), Support for Good Product Structure Creation, Proceedings of the 2nd WDK Workshop on Product Structuring, Delft, Holland

[8] Gershenson, J., Prasad, G. \& Zhang, Y. (2014). Product Modularity: Measures and Design Methods, Journal of Engineering Design, Vol. 15, No. 1, Feb. 2004, pp. 33-51., ISSN 0954-4828, DOI 10.1080/0954482032000101731

[9] Lange, M. \& Imsdahl A. (2014). Modular Function Deployment: Using Module Drivers to Impart Strategies to a Product Architecture, in Advances in Product Family and Product Platform Design: Methods and Applications, Simpson T., Jiao J., Siddique Z., Hölttä-Otto K. (Ed.), pp. 91-118, Springer, ISBN 9781461479376, New York

[10] Ito, Y. (2008). Modular Design for Machine Tools, McGraw-Hill Companies, Inc., ISBN 9780071496605, New York

[11] Meehan, J.; Duffy, A. \& Whitfield, R. (2007). Supporting “Design for Re-use” with Modular Design, Concurrent Engineering, Vol. 15, No. 2, 2007, pp. 141-155, ISSN 1063-293X, DOI 10.1177/1063293X07079319

[12] Chiu, M. \& Okudan, G. (2014). An Investigation on the Impact of Product Modularity Level on Supply Chain Performance Metrics: An industrial Case Study, Journal of Intelligent Manufacturing, Vol. 25, No. 1, 2014, pp. 129145, ISSN 09565515, DOI 10.1007/s10845-012-0680-3

[13] Andreasen, M. (2011) 45 Years with Design Methodology, Journal of Engineering Design, Vol. 22, No. 5, May 2011, pp. 293-332, ISSN 0954-4828, DOI 10.1080/09544828.2010.538040

[14] Pahl, G.; Beitz, W.; Feldhusan, J. \& Grote, K. (2007) Engineering Design: A Systematic Approach, Third Edit., Springer, ISBN 978-1-84628-319-2, Berlin, 2007. 
[15] Ulrich, K. \& Eppinger, S. Product Design and Development, Sixth Edit., McGraw-Hill, ISBN 9780078029066 , 2015.

[16] Doi, Y. (1963). On application of BBS, Toyoda Technical Reports, Vol. 4, No. 3, 1963, pp. $22-32$.

[17] Pajaziti, A.; Asllani, T. \& Gjelaj, A. (2017). Design and Construction of a Modular Cost-Effective CNC Machine, Proceedings of the 28th DAAAM International Symposium, pp. 0229-0236, B. Katalinic (Ed.), Published by DAAAM International, ISBN 978-3-902734-11-2, ISSN 1726-9679, Vienna, Austria DOI: 10.2507/28th.daaam.proceedings.031

[18] Stake, R. (2000) On Conceptual Development of Modular Products, Ph.D. Dissertation, Department of Production Engineering, KTH, Stockholm, Sweden, 2000.

[19] Smith, H. (2013). Property as Platform: Coordinating Standards for Technological Innovation, Journal of Competition Law and Economics, Vol. 9, No. 4, 2013, pp. 1057-1089, ISSN 17446414, DOI 10.1093/joclec/nht032

[20] Simpson, T.; Jiao, J.; Siddique, Z. \& Holtta-Otto, K. (2014) Advances in Product Family and Product Platform Design, Springer, ISBN 978-1-4614-7936-9, DOI 10.1007/978-1-4614-7937-6, New York, 2014.

[21] Costes, M., Taganza, J., Prillieux, J.-M. \& Thibault, B. (2014). Modular Design of Automotive Platforms: An innovative approach to reduce cost and time to market. Carmakers' strategies. (Production in Europe), Inovev, http://www.inovev.com/, Accessed on: 2016-10-04

[22] Steinparzer, F., Ardey, N., Mattes, W. \& Hiemesch, D. (2014). The new BMW Efficient Dynamics Engine Family, MTZ worldwide, Vol. 75, No. 5, May 2014, pp. 18-23., ISSN 2192-9114, DOI 10.1007/s38313-014-0146-4

[23] Sanchez, R. \& Mahoney, J. (1996). Modularity, Flexibility, and Knowledge Management in Product and Organization Design, Strategic Management Journal, Vol. 17, No. S2, 1996, pp. 63-76, ISSN 01432095, DOI 10.1002/smj.4250171107

[24] Harland, P. \& Uddin, Z. (2014). Effects of Product Platform Development: Fostering Lean Product Development and Production, International Journal of Product Development, Vol. 19, No. 5, 2014, pp. 259-285, ISSN 14779056, DOI 10.1504/IJPD.2014.064881

[25] Robertson, D. \& Ulrich, K. (1998). Planning for Product Platforms, Sloan Managament Review, Vol. 39, No. 4, 1998, pp. 19-31, ISSN 0019848X

[26] Shmakov, O.; Korolev, D.; Popov, D.; Kitaev, N. \& Korotkov, A. (2017). Modular Mobile Robotic Kit for Prototyping and Debugging of Control Algorithms, Proceedings of the 28th DAAAM International Symposium, pp.0950-0956, B. Katalinic (Ed.), Published by DAAAM International, ISBN 978-3-902734-11-2, ISSN 1726-9679, Vienna, Austria DOI: $10.2507 / 28$ th.daaam.proceedings. 132

[27] Erixon, G. (1998). Modular Function Deployment: a Method for Product Modularisation, Ph.D. Dissertation, Dept. of Manufacturing Systems, The Royal Institute of Technology, Stockholm, Sweden

[28] Henkel, J.; Baldwin, C. \& Shih, W. (2013). IP modularity: Profiting from Innovation by Aligning Product Architecture with Intellectual Property, California Management Review, Vol. 55, No. 4, 2013, pp. 65-82, ISSN 0008-1256, DOI 10.1525/cmr.2013.55.4.65

[29] Baldwin, C. \& Clark, K. (2000) Design Rules: Volume 1. The Power of Modularity, The MIT Press, ISBN 0262024667, Cambridge, Massachusetts, 2000

[30] Simpson, T. (2004). Product Platform Design and Customization: Status and Promise, Artificial Intelligence for Engineering Design, Analysis and Manufacturing: AIEDAM, Vol. 18, No. 1, 2004, pp. 3-20, ISSN 08900604, DOI $10.1017 / \mathrm{S} 0890060404040028$

[31] Cross, N. (2004) Expertise in design: An overview, Design Studies, Vol. 25, No. 5, Sep. 2004, pp. 427-441., ISSN 0142694X, DOI 10.1016/j.destud.2004.06.002

[32] Elustondo, P. (2004). Modular vending machine, patent application US20060042193

[33] Lo, I., Motagnino, F. \& Paredes, F. (2013). Modular vending machine, patent application WO2015019377

[34] Segal, M., Mockus, D. \& Greenberg, R. (2010). Modular vending with centralized robotic gantry, patent US8392019

[35] Klushin, G.; Fortin, C. \& Tekic, Z. (2018). Design Optimization of Size-Adjustable Parts, Proceedings of the 20th International Dependency and Structure Modeling Conference, DSM'18, in press.

[36] Baldwin, C. \& Henkel, J. (2015). Modularity and intellectual property protection, Strategic Management Journal, Vol. 36, No. 11, Nov. 2015, pp. 1637-1655., ISSN 01432095, DOI 10.1002/smj.2303 